\title{
“O Corvo e a Raposa": a ressignificação dos personagens no videoclipe Appât de Velours
}

\author{
Melissa Marangoni Leme ${ }^{\mathrm{i}}$
}

\begin{abstract}
RESUMO
Desde a década de 1980 produzem-se videoclipes musicais, contudo, após a popularização de plataformas como o Youtube, suas difusões tornaram-se mais frequentes. Visto que adaptações de obras literárias são comuns em produções audiovisuais, como o cinema, em relação a esta mídia não seria diferente: é possível encontrar videoclipes que são transposições de poemas, romances e até mesmo fábulas. Isto posto, este trabalho apresenta a análise da transposição midiática de "O Corvo e a Raposa", de La Fontaine, para o videoclipe Appât de Velours, dos artistas Zaz e Alex RenarT. Parte-se da hipótese que, para a construção da nova mídia, houve uma ressignificação dos personagens e, através desta mudança, o clipe musical ressignifica a mensagem da fábula.
\end{abstract}

Palavras-chave: Intermidialidade; La Fontaine; O Corvo e a Raposa; Videoclipe.

\begin{abstract}
Video clips have been produced since the 1980s, however after the popularization of platforms as Youtube, their disseminations became more frequent. Bearing in mind adaptations of literary works are common in audiovisual productions, such as cinema, with this media it would not be different: it is possible to find video clips that are transpositions of poems, novels and even fables. Therefore, this work aims to analyze the media transposition of "The Crow and the Fox", by La Fontaine, for the video clip Appât de Velours, by Zaz and Alex RenarT. It was assumed that, for the construction of the new media, there was a resignification of the characters and, through this change, the music video presents a new meaning for the fable's message.
\end{abstract}

Keywords: Intermediality; La Fontaine; The Crow and the Fox; Videoclip.

\section{INTRODUÇÃO}

\footnotetext{
${ }^{i}$ Graduada em Letras - Português/Francês pela Universidade Federal de São Paulo (UNIFESP). Mestranda em Letras, na linha de pesquisa de Linguagem em Novos Contextos pela mesma universidade. ORCID: https://orcid.org/0000-0003-3938-8738 | melissa.marangoni@hotmail.com
} 
Em março de 2020, a Organização Mundial da Saúde (OMS) declarou a doença causada pelo vírus COVID-19 como pandêmica. A própria organização, então, sugeriu o isolamento social como medida de prevenção à doença, dado pelo fato que não existia cura, nem tratamento eficaz para a população. Desta forma, muitos países aderiram a esta prática e entraram em quarentena; diversas aulas foram feitas de maneira remota e grande parte dos profissionais passaram a realizar o teletrabalho. As recomendações para sair de casa eram apenas para serviços essenciais, como idas aos supermercados, farmácias, dentre outros. Apesar de diminuir os riscos de infecção, o isolamento social agravou os sintomas de pessoas que sofrem de distúrbios mentais, tais como depressão, ansiedade e estresse, sendo até o motivo de novos casos registrados (GONZÁLEZ-SANGUINO, 2020). Todavia, é importante afirmar que a arte teve um papel importantíssimo para a população durante essa etapa do ano. De acordo com pesquisas realizadas pela Universidade Federal do Paraná, a arte contribui para a saúde mental, além de humanizar e aumentar a qualidade de vida da população (LUZ, 2020).

A música está fortemente atrelada à sociedade. Sabe-se que as civilizações antigas possuíam suas formas de manifestações artísticas; a espécie humana, inclusive, passou a ter uma consciência musical em torno de 40.000 anos atrás, porém apenas em 9.000 a.C. é que ela foi capaz de distinguir os fenômenos sonoros, tais como as propriedades do som, as diferenças entre os timbres; a partir de então, seus conhecimentos foram se aprimorando ao passar dos tempos e transmitidos para as gerações seguintes (CANDÉ, 2001, p. 46). De acordo com Areais (2016), a música é capaz de proporcionar memórias intensas e sentimentos profundos que, por sua vez, não podem ser atingidos de outras formas. Estudos que estão sendo realizados recentemente indicam que, durante o ano de 2020, no período da pandemia causada pelo vírus COVID-19, a música teve um papel importantíssimo, sendo utilizada como estratégia para ajudar o bem-estar da população (CLARO; ESTEVENS, 2020). Sendo assim, é importante enfatizar que os estudos nas áreas de ciências humanas e suas relações com as artes se mostram de extrema importância para a sociedade em que vivemos.

Dentre as diversas formas de expressões artísticas, as adaptações circulam entre as mais variadas mídias: um romance pode ser adaptado para um filme ou para uma história em quadrinhos; um jogo de videogame pode se tornar um seriado televisivo; uma fábula pode ser adaptada em canção. Neste processo adaptativo encontra-se a fábula de 
La Fontaine, "O corvo e a Raposa", transposta para uma canção francesa Appât de Velours. Resumidamente, a história retrata um corvo que possuía um pedaço de queijo em seu bico; o queijo caiu no chão depois que uma raposa conseguiu persuadi-lo a cantar, com o objetivo de roubar o queijo do corvo. Esta história, datada do século XVII, tinha suas significações para a época; ao ser transposta para uma mídia do século XXI (o videoclipe), ocorre um processo de ressignificação, sobretudo dos personagens. Deste modo, o presente artigo apresenta como os personagens foram ressignificados na mídia nova e quais foram os impactos gerados sobretudo na mudança da mensagem.

A primeira seção deste artigo busca contextualizar os conceitos de adaptação literária e intermidialidade que são os principais norteadores desta pesquisa. Partiu-se das concepções de Hutcheon (2013) e Rajewsky (2020) para discutir o tema em questão. Em seguida, será apresentado um breve contexto histórico do videoclipe musical para compreender o que essa mídia representa atualmente. Em um terceiro momento, uma análise comparativa entre a fábula de La Fontaine e o videoclipe musical é delineada. Busca-se demonstrar como o processo de ressignificação dos personagens foi feito tendo como resultado, uma mídia diferente, com suas próprias significações.

\section{ADAPTAÇÃO E INTERMIDIALIDADE}

As adaptações circulam entre as mais diversas mídias e, de acordo com Vieira (2010), elas se adequam aos contextos de certa época e às mudanças culturais e temporais. É possível arriscar dizer que, ultimamente, as adaptações também se adequaram às mudanças tecnológicas da sociedade contemporânea. Diversos são os motivos que levam uma obra a ser adaptada, consoante Hutcheon (2013); pode-se levar em conta os atrativos econômicos como um desses fatores, por exemplo, quando um vídeo game é adaptado em filme e vice-versa, a circulação de capital aumenta. Para a autora, "as adaptações não são apenas produzidas pelo desejo capitalista de lucrar" (HUTCHEON, 2013, p. 129, grifos da autora), há ainda os fatores de levantar o capital cultural, além dos motivos pessoais e políticos.

No entanto, apesar de ser uma área fortemente analisada nos últimos anos, as pesquisas no ramo das transposições literárias se focalizaram em estudar apenas aquelas que eram ditas como artes superiores. Hutcheon cita que "[...] parece que adaptar Romeu 
e Julieta para uma forma de arte elevada, como a ópera ou o balé, é algo mais ou menos aceitável, ao passo que adaptar a peça para um filme [...] não o é.” (p. 23).

Umberto Eco (2007) exemplifica os tipos de adaptação em romance para o cinema, romance para o teatro, fábula para balé, música clássica para desenho animado. Pensar que adaptar é um processo que se limita apenas às artes "nobres", exclui outros tipos de produções riquíssimas, como, por exemplo, um romance que é adaptado em vídeo game ou, uma fábula que é transposta para um videoclipe. Por esta razão, para que possa ocorrer um estudo que envolva diversos tipos de mídias, é que a teoria que servirá de base a partir deste ponto será a da intermidialidade.

Inicialmente, as pesquisas sobre a intermidialidade surgiram no campo dos estudos literários, foi em 1812 que o termo intermídia apareceu pela primeira vez em um escrito de teoria literária de Samuel Taylor Coleridge no qual o autor discutia sobre alegoria nas poesias de Edmund Spenser. Em seguida, o termo só foi utilizado mais uma vez em 1966, por Richard Dick Higgins, em um ensaio intitulado intermídia. O autor afirma que o happening foi um movimento que surgiu como intermídia, pois para o autor, ela seria a relação entre os meios que se unem para criar um único meio (HIGGINS, 2012). Naquela época, Higgins sugeriu que "o uso de intermídia seja mais ou menos universal através das belas artes" (p. 45).

As pesquisadoras Ramazzina Ghirardi, Rajewsky e Diniz (2020) notam que em 1981 Higgins renovou o uso do termo

\footnotetext{
Agora falando de intermidialidade - embora ele ainda o utilize em um sentido muito específico para referir-se a obras "nas quais os materiais de várias formas de arte mais estabelecidas são 'conceptualmente fundidas' em vez de serem simplesmente justapostas”. (RAMAZZINA GHIRARDI, RAJEWSKY, DINIZ, 2020, p. 14)
}

Doravante, o conceito de intermidialidade é utilizado de maneiras diversas, sendo assim, de acordo com Rajewsky (2020, p. 63), deve-se considerar "a gênese do debate cuja emergência vai de par com o entrelaçamento de vários discursos heterogêneos". A autora ainda demonstra que a intermidialidade desenvolveu-se, inicialmente, em três campos de pesquisas diferentes: primeiramente nos estudos interarte; em segundo lugar nas relações entre o cinema e a literatura; e por fim, a partir dos estudos sobre a intertextualidade. 
O crítico austríaco Hansen-Löve foi a primeira pessoa que utilizou o conceito de intermidialidade "no sentido que se tornaria relevante para os debates nos anos 1990. O pesquisador usa intermidialidade em analogia com intertextualidade para capturar as relações entre literatura e artes visuais" (RAMAZZINA GHIRARDI et al., 2020, p. 14). Cunhada ainda nas pesquisas estruturalistas, a intertextualidade foi um conceito trazido por Julia Kristeva, em 1969, para a autora "texto se constrói como um mosaico de citações", e ainda que "todo texto é absorção e transformação de um outro texto" (KRISTEVA, 2012, p. 68). Genette, por exemplo, definiu a intertextualidade "como uma relação de copresença entre dois ou vários textos, isto é, [...] como presença efetiva de um texto em outro" (GENETTE, 2010, p. 12).

Nota-se que nos exemplos citados acima, ambos pesquisadores se limitam às relações entre os textos, fato que poderia excluir diversos estudos. Por outro lado, a intermidialidade "serve para designar as configurações, procedimentos e processos implicando várias mídias, nos quais entre o jogo, portanto, um atravessamento das 'fronteiras' midiáticas” (RAJEWSKY, 2020, p. 64).

Em um sentido mais amplo, é possível compreender a intermidialidade como “todos os tipos de inter-relação e interação entre mídias [...]" (CLUVER, 2012, p. 9). No entanto, pensar em intermidialidade somente como um termo genérico exclui certas possibilidades de análise. Por essa razão, Rajewsky (2020) propõe uma abordagem mais específica dos estudos, criando subcategorias, para que seja possível reconhecer uma quantidade maior de fenômenos intermidiáticos que tem por objetivo compreender a mídia. Assim, a autora propõe três subcategorias da intermidialidade: a transposição midiática (adaptações cinematográficas de textos literários, por exemplo), as referências intermidiáticas na combinação de mídias. Em relação a esta última, Rajewsky (2020, p. 74) afirma que há uma copresença de diferentes mídias "que faz[er] emergir, por sua concomitância, uma constelação intermidiática".

A combinação de mídias, consoante Clüver,

encontra-se em grande parte dos produtos culturais, desde as danças e canções rituais pré-históricas até muitos textos eletrônicos digitais (dependendo do ponto de vista); ela é per definitionem um aspecto marcante de todas as mídias plurimidiáticas. (CLÜVER, 2006, p. 15) 
Dentre diversos tipos de combinação de mídias, pode-se citar o videoclipe como um exemplo, tendo em vista que ele apresenta em sua totalidade diversas mídias juntas, tais como a música (que por sua vez possui seus próprios elementos: harmonia, melodia e ritmo), imagens, gestos, animações, etc.

Visto esse breve resumo sobre o início dos estudos intermidiáticos, ainda se faz necessário levantar a seguinte questão: o que é mídia? A palavra mídia está ligada ao termo intermidialidade. Para Elleström (2017 apud RAMAZZINA GHIRARDI et al., 2020) não seria preciso encontrar uma definição de mídia que servisse para todas as áreas de pesquisa que estudam tal conceito, para o autor,

\footnotetext{
Mídia é um termo empregado de forma ampla, e seria inútil tentar encontrar uma definição direta que abrangesse todas as noções que se encontram por trás dos diferentes usos da palavra. Noções dessemelhantes de mídia e de midialidade são utilizadas em campos diferentes de pesquisa, e não há motivo para interferência nesse sentido uma vez que elas atendem as suas tarefas específicas. (ELLESTRÖM apud RAMAZZINA GHIRARD et al., 2020, p. 16)
}

Desta forma, ao realizar uma pesquisa no âmbito dos estudos intermidiáticos, fazse necessário encontrar a definição que se enquadre melhor com o que está sendo estudado. Por exemplo, Guelton (2013, p. 12 apud RAMAZZINA GHIRARDI, p. 17) define mídia como "suportes semióticos para as obras artísticas". Clüver (2012), por sua vez, acredita que a mídia é o "que transmite para e entre seres humanos um signo (ou um complexo sígnico) repleto de significado, com o auxílio de transmissores apropriados" (BOHN, MÜLLER, RUPPERT, 1998 apud CLÜVER, 2012, p. 9). Nota-se que a primeira versão se aproxima da linha de estudo da intermidialidade relacionada aos estudos interartes, enquanto a definição adotada por Clüver é passível de ser utilizada de uma maneira mais ampla, como neste artigo que trabalha com duas mídias distintas, a fábula e o videoclipe.

\section{VIDEOCLIPE: UM BREVE CONTEXTO HISTÓRICO}

Apesar de ser uma prática muito popular atualmente, o videoclipe não é um objeto que costuma ser explorado pelos estudos linguísticos. Mozdzenski (2013) aponta que há uma grande dificuldade em encontrar literatura que aborde o tema e uma possível razão 
para que isso ocorra é o fato dele sofrer preconceito, sendo considerado como um produto cultural inferior.

A sua origem está ligada à propaganda de compositores e músicos. Foi na década de 1980 que se obteve maior destaque. Nesta época, quando ele emergiu "como proposta audiovisual, tinha, no plano da linguagem, uma educação rápida e instantânea, e, no plano mercadológico, o ritmo igualmente veloz do prazo de validade como ferramenta de divulgação musical” (SOARES, 2000, p. 24 apud CÔRREA, 2008, p. 2).

O canal de televisão MTV teve um papel essencial nessa difusão. Na época, para aumentar a audiência, a rede dedicou horários e programas que exibiam videoclipes de diversas bandas e cantores para os telespectadores. Em pouco tempo, os produtores musicais tomaram consciência de que o lançamento destes produtos ajudava na venda dos discos. Este fato caracteriza essa primeira fase dos videoclipes, que foram considerados como uma estratégia de marketing, entretanto, rapidamente, os videoclipes se consolidaram como um produto da indústria audiovisual.

Após o advento da internet, os videoclipes musicais começaram a ser publicados na plataforma Youtube. A popularização do YouTube,

[C]onstitui uma mola-propulsora essencial da cultura do compartilhamento audiovisual contemporâneo não apenas por oferecer um espaço de espraiamento de material, mas especialmente por possibilita a veiculação de um sem-número de formatos, estéticas e linguagens. (HOLZBACH \& SILVA, 2017 , p. 98)

O videoclipe em sua essência é uma combinação de mídia, Mozdzenski (2013) ressalta que ele possui um excelente material para investigar as múltiplas semioses, isto porque ele orquestra em um mesmo discurso textos verbais (letra da canção e melodia); textos verbais acessórios; componentes paratextuais; músicas; sons eventuais; além das imagens, cores. Sendo assim, essa mídia se mostra extremamente interessante para as pesquisas linguísticas.

\section{3. "O CORVO E A RAPOSA" ENTRE AS MÍDIAS}

Fábula é uma palavra vinda do latim fabŭla que, por sua vez, significa "conversa", "relato", "história". Ao ver sua definição, pode-se aproximar o gênero da literatura de 
tradição oral. Atualmente, coloca-se a fábula ao lado dos contos, mas esquece-se que ela fazia (e ainda faz) parte da literatura de tradição oral. Assim como os contos de fadas, por exemplo, que eram histórias contadas pelas pessoas e transmitidas oralmente, até que escritores, como Charles Perrault (França) e os Irmãos Grimm (Alemanha), imortalizaram-nas no texto escrito.

Como um gênero, a fábula pode ser entendida como "uma narração alegórica, cujos personagens são animais, apresentando no final uma lição de ética comportamental (moral da fábula)" (D’ONOFRIO, 209, p.124). Alceu Dias Lima (apud DEZOTTI, 2017, p. 214) diz que a fábula consiste em "um discurso composto de outros três - o narrativo, o moral e o metalinguístico -, podendo os dois últimos estar ou não materializados em texto". A tradição das fábulas remete à época dos gregos antigos. As mais conhecidas são aquelas atribuídas ao escritor grego Esopo que são conhecidas principalmente por conta do livro Fábulas de Esopo o qual serviu de inspiração para diversos fabulistas, dentre eles, Jean de la Fontaine.

As fábulas de La Fontaine, de acordo com Cunha (2015, p. 24), são reescrituras, "mas criadas em um estilo novo, por meio de versos livres, cuja sequência contém rimas variadas". O autor ainda demonstra que na grande maioria das vezes, os animais são os personagens das narrativas, fato que contribui para que a mensagem da fábula, sejam elas críticas ou denúncias, seja velada, como se nada importante estivesse sendo dito. Além disso, é possível encontrar nos textos do fabulista uma grande dualidade, vistas, muitas vezes, na natureza animal, "macho/fêmea, o animal humanizado (pois ele demonstra sentimentos), alma e corpo, vida/morte, por meio do duplo e da mistura de características humanas em animais e vice-versa, instaura-se uma oposição, pode-se dizer tudo sem se comprometer" (p. 30). Um exemplo desta dualidade "está presente na história do Corvo e da Raposa, e na oposição entre uma pessoa simples e uma astuta" (p. 30).

A fábula conta a história de um corvo que estava pousado num galho de uma árvore com um pedaço de queijo no bico. Uma raposa sente o cheiro do queijo e, atraída pelo odor, vai em direção do pássaro, para tentar persuadi-lo a soltar o pedaço de queijo. Então, ela elogia o corvo dizendo que ele tinha uma bela voz e que seria ótimo ouvi-lo cantar. Encantado pelas palavras, o corvo abre o bico para cantar e solta o pedaço de queijo que é pego pela raposa. 
Tal história é retomada em 2013 pelos artistas franceses Zaz e Alex Renart, inicialmente em forma de canção e, dois anos mais tarde, lançam o videoclipe na plataforma Youtube. O objetivo deste artigo é demonstrar a maneira pela qual os personagens foram ressignificados nesta nova mídia. Um fato importante a ser constatado é que, a música é cantada em um dueto, dando a impressão de que os personagens do vídeo estão em uma conversa.

O vídeo começa ${ }^{1}$ em um escritório de um psicólogo no qual o personagem - que descobriremos ao fim a história ser a raposa - está deitado sobre um divã e inicia a conversa com os seguintes versos: "Mestre Corvo, numa árvore empoleirado / no bico segurava um belo queijo / Mestre Raposa atraída pelo cheiro / Assim lhe diz de bom entusiasmo"2 (ZAZ, 2013, tradução nossa). É importante notar que, na letra em francês, há uma pequena alteração no nome do personagem da fábula, Renard: a letra D torna-se T, fazendo uma alusão direta ao nome do cantor, Alex RenarT. Essa estratégia imagética se perde quando a frase é traduzida para português porque o nome do autor, Renart, não surte o mesmo efeito com o substantivo Raposa (renard, em francês).

Não se pode separar, em um videoclipe, a música da letra, pois as duas mídias estão juntas. É possível entender que neste trecho, há um indício de ressignificação do personagem Renard (raposa), pois enquanto em um primeiro momento ele era uma raposa de uma fábula, no videoclipe ele é o personagem que está passando por problemas e sendo consultado por um psicólogo.

Pereira e Neves (2003, p. 67) analisam o personagem raposa como traiçoeiro, pois "com astucia, ela manipula as ações do corvo a fim de conseguir o que quer, ou seja, o pedaço de queijo, sem que, para isso, fosse necessário muito esforço”. Ainda de acordo com as autoras, "a cobiça leva a raposa a proferir um discurso cínico em relação às características do corvo, com o qual tem a intenção de manipular o comportamento do outro de forma amigável, distanciando-se aparentemente, de sua culpa" (p. 68).

Em contrapartida, percebe-se que, no videoclipe, este personagem, em um primeiro momento, não é astuto. Esse fato é evidenciado principalmente pela linguagem corporal que ele transmite: em certos momentos, ele demonstra timidez, por exemplo, entre o minuto $1 \min 10$ e $1 \min 15$ do videoclipe, Renart está encolhido embaixo do divã, com uma expressão que indica até mesmo um certo pavor.

Enquanto na fábula o corvo foi representado como vítima, agora ele é responsável 
por aconselhar Renart em um papel de psicólogo. Essa transformação é marcada igualmente na letra da canção: no primeiro verso ele era chamado de Mestre Corvo, no decorrer na música, ele torna-se Senhora Corvo, fazendo alusão direta à figura feminina do videoclipe que representa a psicóloga.

\author{
Senhora Corvo, eu meditei bem \\ eu me virei em círculos e eu até mesmo cogitei \\ mas eu não encontrei soluções \\ para os meus problemas de qualquer maneira. (ZAZ, 2013, grifos nossos; \\ tradução nossa) ${ }^{3}$
}

Durante grande parte da canção, Renart não encontra a solução para os seus problemas, os versos "eu não encontrei soluções para os meus problemas de qualquer maneira" são repetidos durante a canção, pode-se dizer que eles chegam o mais próximo de um refrão. Até o momento em que a psicóloga indica estar nervosa com as lamentações de seu paciente; este fato fica evidenciado pelo aumento do ritmo da música e a tonalidade utilizada pela cantora nestes próximos versos:

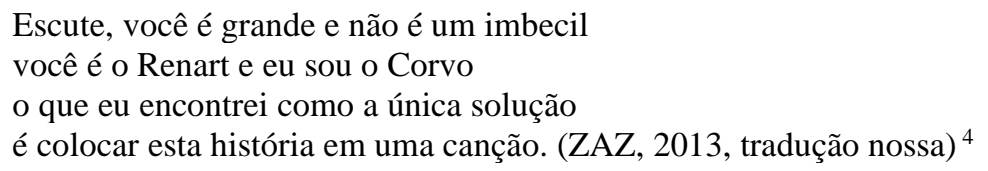

Como visto acima, a solução encontrada pela psicóloga para as questões de seu paciente é a de transformar sua história em canção. Neste momento, é possível perceber a ocorrência da metalinguagem linguística, pois a história do personagem, retratado como a raposa, já foi colocada em canção.

A evolução do Renart é retratada também pelas suas vestimentas: no início da história, ele traja roupas mais sérias em um momento em que, na canção, ele está tendo dificuldade para lidar com seus problemas. Em seguida, ele faz uso de roupas mais leves e coloridas, e no fim do videoclipe, este personagem está vestindo roupas despojadas e extravagantes. Sua camiseta é branca e possui a imagem de uma raposa estampada no centro, seus cabelos estão bagunçados e para o alto, dando a impressão de uma certa rebeldia do personagem.

Os artistas apresentam para seu público, uma composição que, inicialmente demonstrava um Renart que passava por certos problemas e que estava buscando ajuda em um psicólogo, e, através de recursos intermidiais (expressos pelas vestimentas, mas 
não apenas desta forma), demonstrou sua evolução até ele tornar-se um personagem um pouco mais próximo da história de La Fontaine: a raposa astuta.

\section{CONSIDERAÇÕES FINAIS}

Em um momento em que a humanidade passou por uma pandemia que trouxe enormes impactos para a saúde e a economia global, a arte foi extremamente necessária para apoiar a população. Por esta razão é necessário reforçar a importância nos estudos em ciências humanas e artísticas, pois elas sempre se mostram importantes para a nossa sociedade.

Este artigo utilizou duas grandes expressões artísticas, a fábula - atualmente, gênero literário fortemente divulgado, principalmente no imaginário da literatura infantojuvenil - e a música. Além disso, foi incluída uma nova forma de expressão, o videoclipe que teve um crescimento forte nos últimos anos. A intermidialidade foi uma ciência que se iniciou no âmbito dos estudos literários e expandiu-se para as outras áreas de estudo. Por ser considerado como um termo "guarda-chuva", ou seja, que pode possuir diversas significações a depender da área de pesquisa utilizada, é importante dizer que se partiu do conceito de combinação de mídias definido por Clüver e retomado por Rajewsky.

A história de "O Corvo e a Raposa" foi utilizada para introduzir os animais na canção, e após seus quatro primeiros versos, a música tomou um rumo diferente, apresentando uma nova versão da fábula. O personagem da raposa é mostrado, nos escritos de La Fontaine, comportando-se de modo traiçoeiro para conseguir o pedaço de queijo que desejava. Por outro lado, no videoclipe, nos é apresentado um personagem calmo e, aparentemente, acanhado, o qual, com a ajuda de uma psicóloga (retratada como o Corvo) liberta-se de seus problemas a partir do momento que lhe é sugerido contar sua história em uma canção.

\section{Referências}

AREIAS, J. C. A música, a saúde e o bem estar. Nascer e Crescer. Porto, v. 25, n. 1, p. 7-10, mar. 2016. Disponível em:

http://www.scielo.mec.pt/scielo.php?script=sci_arttext\&pid=S08720754201600010000 $1 \& \operatorname{lng}=$ pt\&nrm=iso. Acesso em: 08 out. 2020. 
CLARO, C; ESTEVES, M. L. A música na lupa da psicologia face à pandemia: COVID 19!. In: INFAD Revista de Psicologia. n 1. vol. 1, p.143-154, 2020. Disponível em: http://www.infad.eu/ RevistaINFAD/OJS/index.php/IJODAEP/article/view/1770/1563. Acesso em: 08 out. 2020

CLÜVER, C. Inter textus / interartes / intermedia. Aletria: Revista de Estudos de Literatura, [S.1.], v. 14, p. 10-41, dez. 2006. Disponível em: <http://www.periodicos.le tras.ufmg.br/index.php/aletria/article/view/1357>. Acesso em: 21 set. 2020.

Intermidialidade. PÓS: Revista do Programa de Pós-graduação em Artes da EBA/UFMG, $\quad$ p. 8-23, 2012. Disponível em: https://periodicos.ufmg.br/index.php/revistapos/article/view/15413/12270. Acesso em 04 abr. 2020.

CUNHA, F. O. Fabulosas crônicas: La Fontaine nas crônicas de Machado de Assis. 2015. 207 f. Dissertação (mestrado) - Universidade Estadual Paulista Júlio de Mesquita Filho, Faculdade de Ciências e Letras de Assis, 2015. Disponível em: <http://hdl.handle.net/11449/124449>. Acesso em: 15 nov. 2020.

DEZOTTI, M. C. C. Os primórdios da fábula na literatura brasileira. Itinerários. Araraquara, n. 44, jan./jun. 2017. p. 211-228.

D’ONOFRIO, S. Dicionário da cultura básica. Rio de Janeiro: Publit. 2009. Disponível em: <http://acervodigital.unesp.br/handle/123456789/38987> Acesso em: 28 set. 2020

ECO, U. Quando muda a matéria. In: Quase a mesma coisa. Rio de Janeiro: Editora Record, 2007.

GENETTE, Gerard. Palimpsesto: a literatura de segunda mão. Belo Horizonte: Edições Viva Voz, 2010.

GONZÁLEZ-SANGUINO, Clara; et. al. Mental health consequences during the initial stage of the 2020 Coronavirus pandemic (COVID-19) in Spain. Brain, Behavior, and Immunity. v. 87, p. 172-176, 2020. [s. 1.]. Disponível em: https://www.sciencedirect.com/science/article/abs/pii/S0889159120308126. Acesso em 02 abr. 2021.

HIGGINS, Dick. Intermídia. In: DINIZ, Thaïs Flores; VIEIRA, André Soares (Org.). Intermidialidade e Estudos Interartes: Desafios da Arte Contemporânea 2. v. 2. Belo Horizonte: Rona Editora: FALE/UFMG, 2012, p. 41 - 50.

HUTCHEON, L. Uma teoria da adaptação. 2 ed. Florianópolis: Ed. da UFSC, 2013.

KRISTEVA, Julia. Introdução à semanálise. 3 ed. São Paulo: Perspectiva, 2012.

LUZ, Breno Antunes da. Arte contribui para humanização e saúde mental, segundo pesquisadoras; UFPR oferece acesso online na quarentena. Universidade Federal do 
Pará, 2020. Disponível em: https://www.ufpr.br/portalufpr/noticias/arte-contribui-parahumanizacao-e-saude-mental-segundo-pesquisadoras-ufpr-oferece-acesso-onlinedurante-quarentena/. Acesso em: 03 abr. 2021.

MENÉRES, M. A. Fábulas de la Fontaine. Porto: Asa, 1999.

MOZDZENSKI, L. As configurações genéricas e multimodais do videoclipe. Signo. online. v. 38, p. 100-117, 2013.

PEREIRA, L., M. M. NEVES. A personagem raposa nas fábulas de Fedro. Idéias: Revista do Curso de Letras, UFSM/SM, v. 18, p. 66-70, 2003.

RAJEWSKY, I. O termo intermidialidade em ebulição: 25 anos de debate. In: FIGUEIREDO, C. A. P.; OLIVEIRA, S. R.; DINIZ, T. F. N. (org.) A intermidialidade e os estudos interartes na arte contemporânea. Santa Maria: Editora UFSM, 2020. p. 55 96.

RAMAZZINA GHIRARDI, Ana Luiza; RAJEWSKY, Irina; DINIZ, Thaïs Flores Nogueira. Intermidialidade e Referências Intermidiáticas: uma introdução. Revista Letras Raras, [S.1.], v. 9, n. 3, p. 11-23, 2020. Disponível em: http://revistas.ufcg.edu.br/ch/index.php/RLR/article/view/1902. Acesso em: 04 abr. 2021.

SILVA, C. M.; HOLZBACH, A. D. Eles chegaram como uma bola de demolição: YouTube, spoofs e o videoclipe Wrecking Ball. Temática - Revista eletrônica de publicação mensal, v. 1, 2017, p. 97-113.

VIEIRA, E. V. C. Das apropriações literárias: algumas considerações a respeitos da literatura e do suplemento de Derrida. Minas Gerais: Em Tese, V. 16, nº 13, 2010.

ZAZ, RENART, A. Appât de Velours. 2015. (3min46). Disponível em: https://www.youtube.com/watch?v=a4Yisrmqpu8\&ab_channel=MichelGUILLERM.

Acesso em: 08 nov. 2020

Recebido em: 17/06/2021

Aceito em: 04/08/2021

\footnotetext{
${ }^{1}$ Disponível em: https://www.youtube.com/watch?v=pROYedAn8Ug\&ab_channel=LOLASANCHEZE. Acesso em 19 mai. 2021.

2 "Maître Corbeau, sur un arbre perché, / Tenait en son bec un fromage / Maître Renart, par l'odeur alléché, / Lui tint à peu près ce langage”.

3 “Madame le Corbeau j'ai bien médité / J'ai tourné en rond et j'ai bien cogité / Mais je n'ai pas trouvé de solutions / À mes problèmes de toute façon."
} 
"O Corvo e a Raposa”: a ressignificação dos personagens no videoclipe Appât de Velours

4 “Écoutez, vous êtes grand et vous n'êtes pas un sot/ C'est vous le Renart moi je suis le Corbeau / Ce que j'ai trouvé comme seule solution / C'est mettre votre histoire en chanson". 